University of Nebraska - Lincoln

DigitalCommons@University of Nebraska - Lincoln

\title{
Influence of Sample Orientation on Prediction of Fresh Ham Lean Content by Electromagnetic Scanning
}

\author{
N. L. Meseck \\ Clarion, IA \\ B. L. Gwartney \\ University of Nebraska-Lincoln \\ Chris R. Calkins \\ University of Nebraska-Lincoln, ccalkins1@unl.edu \\ Phillip Miller \\ University of Nebraska-Lincoln, pmiller1@unl.edu
}

Follow this and additional works at: https://digitalcommons.unl.edu/animalscifacpub

Part of the Animal Sciences Commons

\footnotetext{
Meseck, N. L.; Gwartney, B. L.; Calkins, Chris R.; and Miller, Phillip, "Influence of Sample Orientation on Prediction of Fresh Ham Lean Content by Electromagnetic Scanning" (1997). Faculty Papers and Publications in Animal Science. 587.

https://digitalcommons.unl.edu/animalscifacpub/587

This Article is brought to you for free and open access by the Animal Science Department at DigitalCommons@University of Nebraska - Lincoln. It has been accepted for inclusion in Faculty Papers and Publications in Animal Science by an authorized administrator of DigitalCommons@University of Nebraska - Lincoln.
} 


\title{
Influence of Sample Orientation on Prediction of Fresh Ham Lean Content by Electromagnetic Scanning ${ }^{1}$
}

\author{
N. L. Meseck², B. L. Gwartney3, C. R. Calkins4, and P. S. Miller \\ Animal Science Department, University of Nebraska, Lincoln 68583-0908
}

\begin{abstract}
To evaluate the effect of orientation of hams during electromagnetic scanning on the estimation of dissected lean content, hams were scanned horizontally, posterior first (POS) or dorsal first (DOR), and vertically, medial side (aitchbone) first (MED; standing on the butt face). Weight and percentage of dissected lean were estimated using scan peak for each orientation, ham weight, and fat thickness. The mean scan peak for the MED orienta-
\end{abstract}

tion was approximately twice as great as peaks for the POS and DOR orientations, which suggests that this orientation may offer greater predictive accuracy by reducing the signal to noise ratio. Results, however, indicated that all orientations were equally effective at predicting lean weight and percentage, with $\mathrm{R}^{2}$ values of .95 and .75 and root mean square errors of $.21 \mathrm{~kg}$ and $2.6 \%$, respectively.

Key Words: Pork, Composition, Electrical Conductivity, Electromagnetic Field

J. Anim. Sci. 1997. 75:3169-3173

\section{Introduction}

Predicting the lean content of meat animals and meat cuts has long been a desire of the livestock and meat industries. Electromagnetic scanning (EMS), referred to as total body electrical conductivity (TOBEC), uses rapid, nondestructive methods (Domermuth et al., 1976; Forrest et al., 1989). Total body electrical conductivity is primarily related to the amount of lean tissue present in a carcass or cut. This is due to the greater water and electrolyte content of lean compared with fat (Lin et al., 1992). Tissue passing through the scanner will absorb a given amount of energy proportional to the amount of lean present. Highly conductive materials (i.e., most metal) and highly resistive materials (i.e., fat and bone) will absorb little energy from the field (Funk, 1991).

Investigations have shown that geometry significantly influences TOBEC readings (Khaled et al., 1985; Fiorotto et al., 1987). Gwartney et al. (1995) hypothesized that different orientations of beef ribs during scanning may result in different degrees of predictive accuracy based on reductions of the signal to noise ratio. All orientations were equally effective,

\footnotetext{
${ }^{1}$ Paper number 11664, J ournal series, Nebraska Agric. Res. Div., University of Nebraska, Lincoln 68583-0908.

${ }^{2}$ Current address: 202 1st Street S.E. \#3, Clarion, IA 50525.

${ }^{3}$ Current address: 108 George Street, Dunn, NC 24334.

${ }^{4}$ To whom correspondence should be addressed.

Received September 24, 1996.

Accepted J uly 11, 1997.
}

however, despite a dramatic difference in TOBEC readings. The objective of this study was to determine the precision of prediction for lean weight and the percentage of lean of hams scanned in various orientations.

\section{Materials and Methods}

Hams. Fifty-eight hams from two dissimilar genetic lines of pigs fed six dietary protein levels $(10,13,16$, 19,22 , or $25 \%$ CP) were removed from the left side of 58 chilled pork carcasses in a two-replication experiment. These genetic lines have been described by Chen et al. (1995). Twenty-five hams were evaluated in the first replication; the remaining 33 hams were evaluated from the second replication 4 mo later. Ham thickness (the thickest point from the medial to the distal side), length from the anterior to the posterior end, and weight were recorded. Ham fat thickness was measured at the cut surface, perpendicular to the aitchbone. Internal temperature was recorded by inserting an Omega (Omega Engineering, Stamford, CT) ATT thermocouple (type T) $18 \mathrm{~cm}$ into the butt face to position the thermocouple near the geometric center of the ham.

Scanning Procedures. Hams were scanned using a model MQ-27 scanner (Meat Quality Inc., Springfield, IL ). This consists of a large plexiglass tube $(66 \mathrm{~cm}$ in diameter and $2.1 \mathrm{~m}$ long) around which a copper coil is wrapped (Meat Quality Inc., 1991). Applying a current to the coil generates a $2.5-\mathrm{MHz}$ electromag- 
netic field in this cylindrical chamber (Forrest et al., 1991). The amount of energy absorbed from the coil by the ham was recorded on a Tandy 2810 HD computer (Tandy Corp., Fort Worth, TX). Each ham was scanned on a conveyer twice in each of three orientations. The conveyer positions the product in the approximate center of the electromagnetic field during scanning. For the posterior presentation, the fresh ham was positioned to enter the scanner horizontally, parallel to the long axis of the scanning chamber with the posterior (shank) portion entering the scanner first, fat side down, aitchbone up. Dorsally presented hams were positioned to enter the scanner in the same orientation as the posterior presentation, except that the dorsal side (shank to the left) entered the chamber first. Hams were placed fat side down to provide the most stable position for scanning. No differences in scanning data have been observed from products scanned fat-side up. Hams oriented in the medial position entered the scanner positioned vertically, with the medial side (aitchbone) entering the scanner first, standing on the ham butt face, shank pointing upward. Hams for the latter orientation were placed in plastic tubs to keep them from falling over during scanning. Plastic is nonconductive and did not affect scans. The tubs were scanned empty to verify this. No readings beyond background levels were observed. The peak phase value (maximum absorption) was used in regression equations with ham weight and fat thickness to predict dissected lean weight and lean percentage. Other scanning data were available, but they require some degree of manipulation prior to use. Consistent with other analyses, the peak phase value was used to avoid complicating interpretation of the results.

Dissection. After scanning, the hams were dissected into lean (no visible fat), fat plus skin, and bone. The weight of each was recorded. Fat and skin were weighed together. Lean percentage was calculated as the weight of dissected lean divided by the total ham weight.

Statistical Methods. Regression equations to estimate ham lean weight and lean percentage were developed using SAS (1988). The statistics used to evaluate the data were correlation coefficients, coefficients of determination (CD), root mean square error (RMSE), and Mallows Cp statistic (Mallows, 1964). Prediction models selected were those with maximum $C D$, minimum RMSE, and a $C p$ statistic closest to the number of parameters in the model. The RMSE is an indicator of deviation of the predicted value from the regression line. Mallows $\mathrm{Cp}$ statistic is a measure of bias that may exist in the prediction model. This approach identifies the model with the least bias that explains the greatest amount of variation in the predicted value. The variation due to time of measurement, protein treatment, and genetic line was not addressed with the model because such variation would be expected as part of a normal subsampling of hams and would most often not be identifiable under commercial conditions.

\section{Results and Discussion}

Early TOBEC technology was given the acronym EMME (electronic meat measuring equipment). The early equipment was used mainly for the purpose of measuring lean content in live pigs. J oyal et al. (1987) found that TOBEC readings of live pigs were correlated with weight of lean cuts $(r=.49)$. I nherent problems were associated with measuring of lean weight in live pigs, however. Mersmann et al. (1984) described problems with the repeatability of TOBEC measurements in live pigs due to orientation differences and movement of the animal while in the electromagnetic field. As a result, sedation of live pigs has been used to improve measurements (Keim et al., 1988).

More recently, the interest in predicting lean content of carcasses and their cuts using EMS has been studied. I mprovements in the sensing technol ogy of EMS have greatly increased the accuracy of lean content predictions. Kuei et al. (1990) calculated Rsquare values of $.85, .88$, and .85 for $10 \%$ fatstandardized lean of uneviscerated, warm, dehaired pork carcasses; eviscerated, warm, right sides; and chilled right sides, respectively, using EMS. Kuei et al. (1991) and Berg et al. (1993) also reported that total lean of the carcass, ham, loin, and shoulder of pork carcasses could be calculated using a single carcass scan and other carcass measurements. Similarly, Forrest et al. (1991) demonstrated the use of EMS in evaluating pork carcasses and beef quarters.

Several variables affect EMS readings. Fiorotto et al. (1987) concluded that length, geometry, and ionic composition independently modified the instrument readings. K haled et al. (1985) approached the effects of geometry by controlling the length, radius, and volume of cylindrical conductors and determined that length varied inversely with TOBEC readings for samples with constant volumes. Gwartney et al. (1995) studied the effects of orientation of beef ribs on EMS readings and found that the effect of sample orientation required independent evaluation. Results of that study indicated that different presentations or orientations of samples elicited dramatically different EMS readings. It was hypothesized that the orientation yielding the highest readings would achieve the highest level of predictive accuracy by reducing the signal to noise ratio. They (Gwartney et al., 1995) reported that each orientation was equally effective at estimating lean content. The objective of this study was to determine precision of lean weight and the percentage of lean using hams scanned in various orientations. 
Table 1. Means and standard deviations of ham measurements and scanning measures $(n=58)$

\begin{tabular}{|c|c|c|}
\hline Trait & Mean & $\begin{array}{l}\text { Standard } \\
\text { deviation }\end{array}$ \\
\hline Ham weight, kg & 8.6 & 1.0 \\
\hline Fat thickness, ${ }^{a} \mathrm{~cm}$ & 2.5 & .8 \\
\hline Ham length, ${ }^{b} \mathrm{~cm}$ & 37.8 & 2.8 \\
\hline Ham thickness, ${ }^{c} \mathrm{~cm}$ & 15.0 & 1.5 \\
\hline Posterior position peak & 20.9 & 6.1 \\
\hline Dorsal position peak & 23.9 & 6.5 \\
\hline Medial position peak & 42.5 & 11.2 \\
\hline Lean weight, $\mathrm{kg}$ & 5.0 & .9 \\
\hline Lean, \% & 57.4 & 5.1 \\
\hline
\end{tabular}

${ }^{\mathrm{a}} \mathrm{F}$ at thickness was measured beneath the butt face, perpendicular to the aitchbone.

bLength was measured from the anterior to the posterior end.

'The thickest point from the medial to the distal side.

Means and standard deviations of ham traits are presented in Table 1. Peaks from the dorsal orientation were slightly higher than peaks from the posterior orientation, whereas medial orientation peaks were twice as great as posterior or dorsal peaks. Figure 1 shows three conductivity curves generated by a ham in each orientation. More energy was absorbed from the coil when the hams were oriented in the medial position than in the other orientations. This is in agreement with beef ribs scanned in three orientations (Gwartney et al., 1995). However, Gwartney et al. (1995) saw a more dramatic increase (approximately fourfold) in peak for the blade end position, which would be analogous to the medial position in this study. The much smaller increase with hams is probably due to the more uniform shape of hams vs beef ribs. Ham lean weight was slightly more than one half the total ham weight yet had a SD nearly equal to the SD of total ham weight. Lean percentage was also variable (SD $=5 \%$ ).

Correlations of lean weight and lean percentage with all variables are presented in Table 2 . Peaks

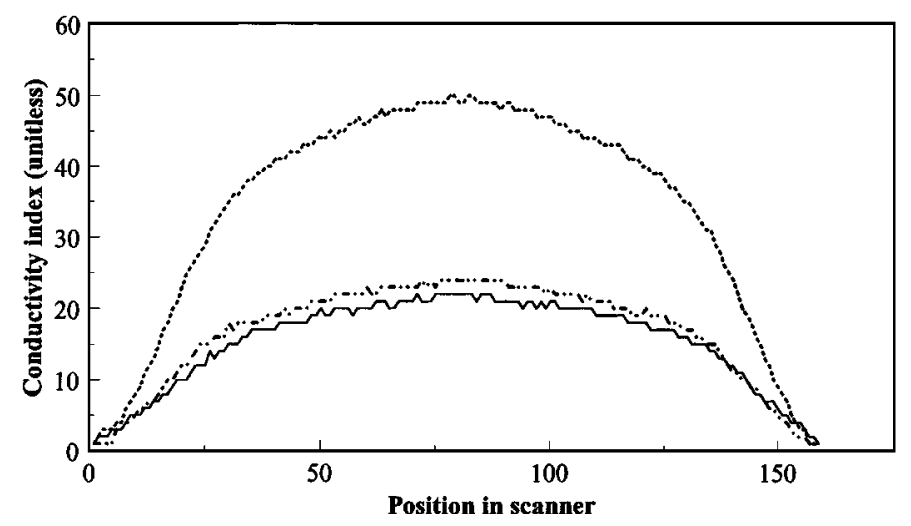

Figure 1. Conductivity curve for a ham scanned in three orientations (medial orientation $=\ldots$. ; d dorsal orientation $=-\cdot-\cdot-\cdot-$; posterior orientation $=\square$ ).

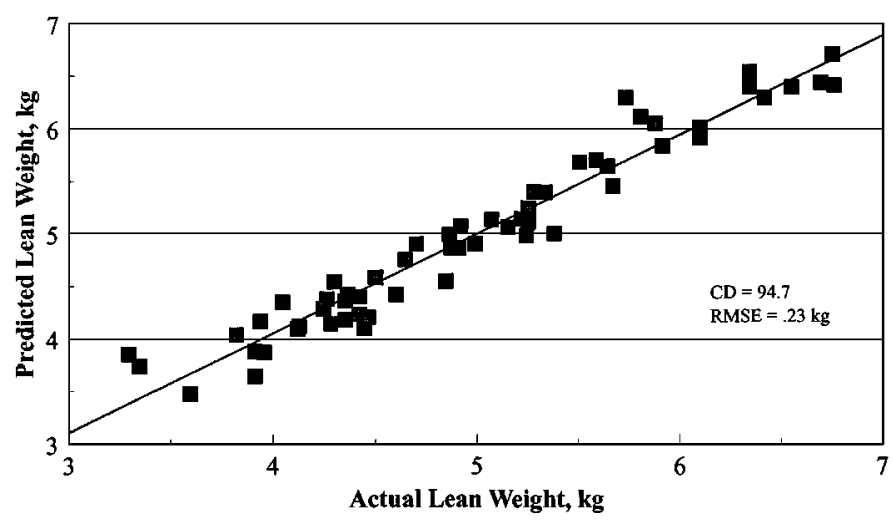

Figure 2. Actual vs predicted ham lean weight using posterior scans. $\mathrm{CD}=$ coefficient of determination; RMSE = root mean square error.

were the highest correlated variables with lean weight and lean percentage but did not differ between orientations. Total ham weight was highly correlated with lean weight, and fat thickness was highly correlated with lean percentage $(P<.001)$. Ham thickness and temperature were not significantly correlated with lean weight or lean percentage. From these correlations, the variables peak, total ham weight, and fat thickness were chosen for the prediction model parameters. Regression equations that included all three variables were less biased (had lower $\mathrm{Cp}$ values) than equations that contained only peak or peak plus one other variable.

Table 3 presents CD and RMSE for equations containing the independent variables and the two- and three-variable equations containing peak to predict ham lean weight and percentage. For prediction of lean weight, peak was the best single variable, and peak and fat thickness seemed equally effective at predicting lean percentage. From the analysis using Mallows $\mathrm{Cp}$ statistic, the best overall equations for lean weight contained peak, weight, and fat thickness,

Table 2. Correlation coefficients of ham measurements and scanning measures to lean content

\begin{tabular}{lcc}
\hline \hline Ham traits $^{\mathrm{a}}$ & Lean weight & Lean \% \\
\hline Weight & .91 & .59 \\
Length & .74 & .56 \\
Ham thickness & .29 & .01 \\
Fat thickness & .59 & .78 \\
Posterior position peak & .95 & .79 \\
Dorsal position peak & .96 & .77 \\
Medial position peak & .95 & .78 \\
\hline
\end{tabular}

${ }^{a} A l l$ traits, except ham thickness, were significant at $P<.001$. Fat thickness was measured beneath the butt face, perpendicular to the aitchbone. Length was measured from the anterior to the posterior end. Ham thickness was the thickest point from the medial to the distal side. 


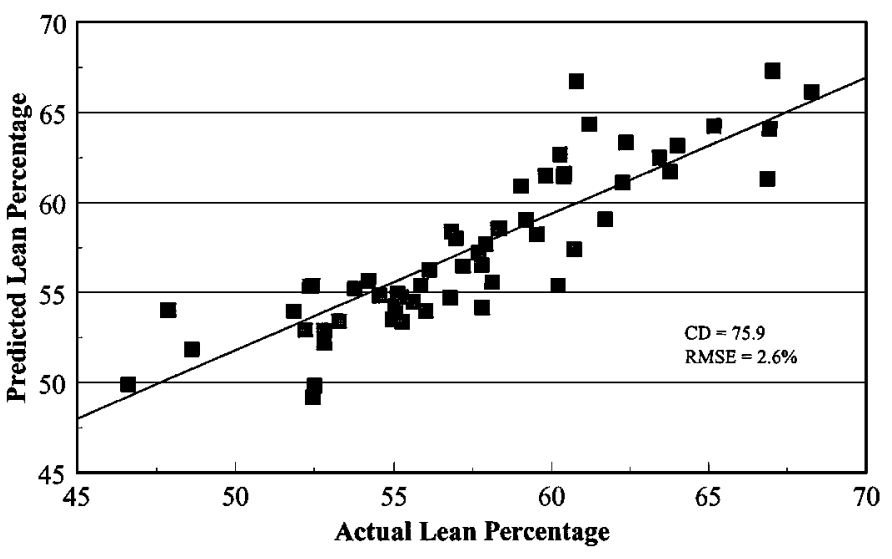

Figure 3. Actual vs predicted ham lean percentage using posterior scans. $\mathrm{CD}=$ coefficient of determination; RMSE $=$ root mean square error.

and the best overall equations for lean percentage contained peak and fat thickness. The overall equations all had CD of $95 \%$ and RMSE of . $21 \mathrm{~kg}$ for weight and the equations for lean percentage had CD of 75 to $77 \%$ and RMSE of 2.5 to $2.6 \%$. These data indicate that orientation, when consistent, has little practical effect on predictive accuracy for ham lean weight and percentage. Figure 2 shows a plot of the actual lean weight vs the predicted lean weight for hams scanned in the posterior orientation. Figure 3 shows a prediction of actual lean percentage vs predicted lean percentage for the same orientation. Plots of actual vs predicted lean for dorsal and medial orientations were similar.

Others have reported estimations of ham lean content using EMS. In a study designed to predict chemically determined fat-free lean weight, Wagner et al. (1992) predicted fat-free ham lean with an $R^{2}$ of .89 and RMSE of .60 kg. Their study, however, examined only the posterior orientation. Berg et al. (1993) similarly accounted for $85.6 \%$ of the variability in dissected ham lean using EMS readings taken on pork carcasses oriented shank first.

Under commercial conditions, it is common to automate determination of ham weight and scan peak. Difficulties arise, however, in making sure the hams are positioned in a uniform manner as they enter the scanner. Accordingly, it is of interest to know the magnitude of error that may arise from improperly positioned hams. To study this question, the data from hams scanned in the posterior position and in the dorsal position were compiled into a single data set. Prediction equations were then created without accounting for position. In other words, hams intended for one orientation but ending up in the alternative orientation were considered as equals in terms of the analysis. Hams in the medial orientation were not included because this situation is not likely to occur in a commercial situation. The results (Table 4) indicate that sufficient similarity in scan peaks allows overall predictive accuracy of $94 \%$ for lean weight and $74 \%$ for the percentage of lean, which are similar to results when orientation was held constant (Table 3). The ideal equations, based on Mallows Cp statistic, were

Table 3. Prediction of lean weight and percentage in hams scanned in three orientations

\begin{tabular}{|c|c|c|c|c|c|}
\hline \multirow[b]{2}{*}{ Orientation } & \multirow[b]{2}{*}{ Model } & \multicolumn{2}{|c|}{ Lean weight, kg } & \multicolumn{2}{|c|}{ Lean percentage } \\
\hline & & $C D^{a}$ & RMSE $^{b}$ & $C D$ & RMSE \\
\hline Posterior & $\begin{array}{l}\text { Peak } \\
\text { Weight } \\
\text { Fat thickness } \\
\text { Peak, weight } \\
\text { Peak, fat thickness } \\
\text { Peak, weight, fat thickness }\end{array}$ & $\begin{array}{l}90.6 \\
83.7 \\
35.1 \\
93.1 \\
90.6 \\
94.7\end{array}$ & $\begin{array}{l}.28 \\
.36 \\
.73 \\
.24 \\
.28 \\
.21\end{array}$ & $\begin{array}{l}62.9 \\
34.6 \\
60.0 \\
68.8 \\
75.8 \\
75.9\end{array}$ & $\begin{array}{l}3.15 \\
4.19 \\
3.27 \\
2.92 \\
2.57 \\
2.59\end{array}$ \\
\hline Dorsal & $\begin{array}{l}\text { Peak } \\
\text { Weight } \\
\text { Fat thickness } \\
\text { Peak, weight } \\
\text { Peak, fat thickness } \\
\text { Peak, weight, fat thickness }\end{array}$ & $\begin{array}{l}91.2 \\
83.7 \\
35.1 \\
92.6 \\
91.4 \\
94.6\end{array}$ & $\begin{array}{l}.27 \\
.36 \\
.73 \\
.25 \\
.27 \\
.21\end{array}$ & $\begin{array}{l}59.4 \\
34.6 \\
60.1 \\
66.0 \\
75.3 \\
75.3\end{array}$ & $\begin{array}{l}3.30 \\
4.19 \\
3.27 \\
3.04 \\
2.60 \\
2.62\end{array}$ \\
\hline Medial & $\begin{array}{l}\text { Peak } \\
\text { Weight } \\
\text { Fat thickness } \\
\text { Peak, weight } \\
\text { Peak, fat thickness } \\
\text { Peak, weight, fat thickness }\end{array}$ & $\begin{array}{l}90.7 \\
83.7 \\
35.1 \\
92.4 \\
91.2 \\
95.0\end{array}$ & $\begin{array}{l}.28 \\
.36 \\
.23 \\
.25 \\
.27 \\
.21\end{array}$ & $\begin{array}{l}60.8 \\
34.6 \\
60.1 \\
67.8 \\
77.5 \\
77.9\end{array}$ & $\begin{array}{l}3.24 \\
4.19 \\
3.27 \\
2.96 \\
2.48 \\
2.48\end{array}$ \\
\hline
\end{tabular}

${ }^{a}$ Coefficient of determination.

bRoot mean square error. 
Table 4. Prediction of lean weight and percentage in hams scanned in either posterior or dorsal orientation

\begin{tabular}{|c|c|c|c|c|}
\hline \multirow[b]{2}{*}{ Model } & \multicolumn{2}{|c|}{ Lean weight, kg } & \multicolumn{2}{|c|}{ Lean percentage } \\
\hline & $C D^{a}$ & RMSE $^{\mathrm{b}}$ & $C D$ & RMSE \\
\hline Peak & 86.1 & .33 & 57.9 & 3.33 \\
\hline Peak, weight & 90.8 & .27 & 60.2 & 3.25 \\
\hline Peak, fat thickness & 86.4 & .33 & 74.3 & 2.61 \\
\hline Peak, weight, fat thickness & 94.2 & .22 & 74.5 & 2.61 \\
\hline
\end{tabular}

${ }^{a}$ Coefficient of determination.

${ }^{b}$ Root mean square error.

the full, three-variable model for lean weight and the combination of peak and fat thickness for lean percentage. It seems that hams, when oriented fatside down for scanning, can be successfully evaluated for composition using EMS.

\section{Implications}

This study indicates that orientation, when defined and kept consistent, does not influence prediction of ham lean weight or the percentage of Iean. Given the impracticality of orienting hams in the aitchbone position, either the posterior or the dorsal position would be preferred.

\section{Literature Cited}

Berg, E. P., J . C. Forrest, and J . E. Fisher. 1993. Prediction of total and primal cut dissected carcass lean pork using an electromagnetic scanner in an on-line industrial configuration. J . Anim. Sci. 71(Suppl. 1):150 (Abstr.).

Chen, H. Y., P. S. Miller, A. J . Lewis, C. K. Wolverton, and W. W. Stroup. 1995. Changes in plasma urea concentration can be used to determine protein requirements of two populations of pigs with different protein accretion rates. J. Anim. Sci. 73: 2631-2639.

Domermuth, W., T. L. Veum, M. A. Alexander, H. B. Hedrick, J . Clark, and D. Eklund. 1976. Prediction of lean body composition of live market weight swine by indirect methods. J . Anim. Sci. 43:966-976.

Fiorotto, M. L., W. L. Cochran, R. C. Funk, H. P. Sheng, and W. J . Klish. 1987. Total body electrical conductivity measurements: Effects of body composition and geometry. Am. J . Physiol. 252: R794-R800.

Forrest, J. C., C. H. Kuei, W. Chen, R. S. Lin, A. P. Schinckel, P. Walstra, H. Kooper, and M. D. J udge. 1991. Electromagnetic scanning: Carcass evaluation. Proc. Symp. Electronic Eval. Meat Support Value-Based Marketing, Purdue University, West Lafayette, IN. p 85.

Forrest, J. C., C. H. Kuei, M. W. Orcutt, A. P. Schinckel, J. R. Stouffer, and M. D. J udge. 1989. A review of potential new methods of on-line pork carcass evaluation. J . Anim. Sci. 67: 2164-2170.

Funk, R. C. 1991. Electromagnetic scanning: Basic and recent advances in technology. Proc. Symp. Electronic Eval. Meat Support Value-Based Marketing, Purdue University, West Lafayette, IN. p 73.

Gwartney, B. L., N. L. Meseck, and C. R. Calkins. 1995. The effects of orientation and storage time on the prediction of beef rib composition using electromagnetic scanning. J. Anim. Sci. 73: 387-392.

J oyal, S. M., S.D.M. J ones, and B. W. Kennedy. 1987. Evaluation of electronic meat-measuring equipment in predicting carcass composition in the live pig. Anim. Prod. 45:97-102.

Keim, N. L., P. L. Mayclin, S. J. Taylor, and D. L. Brown. 1988. Total-body electrical conductivity method for estimating body composition: Validation by direct carcass analysis of pigs. Am. J. Clin. Nutr. 47:180-185.

Khaled, M. A., M. J. McCutcheon, J. Canalas, and C. E. Butterworth, J r. 1985. Effects of body geometry on TOBEC measure ment. In: B. W. Sauer (E d.) Biological Engineering IV: Recent Developments. Proceedings of the Fourth Southern Biomedical Engineering Conference. pp 171-175. Pergamon Press, New York.

Kuei, C. H., J . C. Forrest, A. P. Schinckel, and M. D. J udge. 1990. Influence of processing stage on the predictive accuracy of total body electrical conductivity for pork carcass composition. J . Anim. Sci. 68(Suppl. 1):348-349.

Kuei, C. H., J . C. Forrest, A. P. Schinckel, and M. D. J udge. 1991. Total body electrical conductivity in lieu of dissection for pork carcass composition research. J. Anim. Sci. 69(Suppl. 1):339 (Abstr.).

Lin, R. S., J . C. Forrest, M. D. J udge, R. P. Lemenager, and A. L. Grant. 1992. Application of electromagnetic scanning for prediction of beef carcass composition. Proc. 38th Annu. Int. Congr. Meat Sci. Technol. p. 927.

Mallows, C. L. 1964. Some comments on Cp. Technometrics 15:661.

Meat Quality Inc. 1991. Owners Manual. Meat Quality Inc., Springfield, IL.

Mersmann, H. J ., L. J . Brown, E. Y. Chai, and T. J . Fogg. 1984. Use of electronic meat measuring equipment to estimate body composition in swine. J. Anim. Sci. 58:85-93.

SAS. 1988. SAS/STAT User's Guide (Release 6.03). SAS Inst. Inc., Cary, NC.

Wagner, J. R., A. P. Schinckel, J . C. Forrest, and W. Chen. 1992. Accuracy and biases in the estimation of fat-free total carcass lean from electromagnetic scans of trimmed wholesale hams. J . Anim. Sci. 70(Suppl. 1):224. 